Philosophy and

Phenomenological Research

Philosophy and Phenomenological Research

doi: $10.1111 /$ phpr.12111

(C) 2014 The Authors. Philosophy and Phenomenological Research published by

Wiley Periodicals, Inc. on behalf of Philosophy and Phenomenological Research, LLC.

\title{
Ceteris Paribus, I Could Have Done Otherwise
}

ANN WHITTLE

University of Manchester

In this paper, I explore an alternative to the Principle of Alternate Possibilities for Moral Responsibility-the Ceteris Paribus Principle of Alternative Possibilities for Moral Responsibility. I consider motivations for this principle and answer some objections to it.

\section{The Proposal}

According to the Principle of Alternate Possibilities (PAP),

(PAP) an agent is morally responsible for what she has done only if she could have done otherwise. ${ }^{1}$

Pre-Frankfurt (1969), this principle struck the majority as intuitively obvious. If an agent is blameworthy for an action, then there is an implication that she could have done what morality demanded instead. Ought implies can. So if the agent acted wrongly, they must have been able to refrain from acting wrongly.

This is an open access article under the terms of the Creative Commons Attribution License, which permits use, distribution and reproduction in any medium, provided the original work is properly cited.

1 'Done otherwise' here should be read widely to incorporate those cases where the agent is able to refrain from doing what she did, even though she is unable to bring about some alternative positive state of affairs. For example, we might say the agent could have refrained from lying, but she couldn't have told the truth. In addition, although more controversially, I think we should modify PAP to allow for cases where, although the agent couldn't have done otherwise at the time of action, nevertheless, they could have done otherwise somewhere in the process leading up to the action. For example, whilst the drunk driver couldn't have avoided hitting the child, they could have decided not to take their car to the pub. Unless otherwise stated, then, I shall assume that PAP could be read as: If S is morally responsible for action $\mathrm{A}$, then $\mathrm{S}$ could have done otherwise than $\mathrm{A}$ at $\mathrm{t}$, or $\mathrm{A}$ resulted from an action for which $\mathrm{S}$ could have done otherwise. 
Frankfurt's examples, however, awoke philosophers from their complacent acceptance of PAP. Consider,

Black and Jones: Black implants a device in Jones's brain. If Jones wavers in his intention to kill the dictator, the device will be activated, forcing Jones to remain faithful to his original intention. As it turns out, however, Jones murders the dictator and the device remains inactive. ${ }^{2}$

Intuitively, Jones is morally responsible for murdering the dictator despite not being able to do other than murder the dictator, so PAP is false.

Post-Frankfurt (1969), a huge debate has ensued concerning whether or not any such case really does constitute a genuine counterexample to PAP. Lines have been drawn that cut across the traditional party lines of compatibilism and incompatibilism. Source in/compatibilists maintain that FSCs show us that the ability to do otherwise isn't required for moral responsibility; whilst Leeway in/compatibilists defend PAP, and so scour around for something that the agent could have done differently. But do the lines need to be drawn in this way? The persistence and intensity of the debate attests to the fact that both PAP and FSCs strike us as intuitively compelling. It is difficult to know which one to give up on, because they both seem true.

Fortunately no real paradox presents itself here. There is a simple, and I think rather natural, response to any FSC: Yes the example shows that moral responsibility and the ability to do otherwise can come apart, but nevertheless, normally, if an agent is morally responsible for an action, they can do otherwise. The relationship between the ability to do otherwise and moral responsibility is a little messier than PAP allows.

A conservative, yet so far neglected, replacement to PAP, then, is this:

$\mathrm{CP}(\mathrm{PAP})$ Ceteris paribus, if $\mathrm{S}$ is morally responsible for an action $\mathrm{A}$, then $\mathrm{S}$ could have done other than $\mathrm{A} .^{3}$

2 See Frankfurt 1969 for the original cases. There are many permutations on these cases, only some of which may be regarded as successful counterexamples to the principle of alternate possibilities (PAP). This case of Black and Jones should be considered as a placeholder for the most convincing of Frankfurt style cases (FSCs).

3 One might suggest that PAP, as it figures in our understanding of moral responsibility, is akin to other generics such as 'Raven's are black'. Generic sentences are particularly noteworthy in this context because they tolerate the existence of (permissible) exceptions. Although we are free to make this explicit by adding the 'ceteris paribus' locution, e.g. 'ceteris paribus, ravens are black,' Nickel and others have argued that the ceteris paribus is redundant (e.g. see Nickel 2010, p.9). One may object that viewing PAP as a generic sentence is a non-starter, given that PAP is standardly expressed using a conditional. But the similarity between conditional statements and generics has long been noted (see Carlson and Pelletier 1995, p.49 for references), and PAP can be paraphrased to highlight its similarity with other generics, for instance, we might say that 'agents of morally responsible actions could have refrained from acting how they did'. So it might be thought unnecessary to qualify PAP, since like all generics, it implicitly tolerates exceptions. In what follows, however, I shall continue to refer to $\mathrm{CP}(\mathrm{PAP})$, to make PAP's defeasibility manifest. 
Following a long tradition, the ceteris paribus clause might roughly be interpreted as 'if nothing interferes' (where certain variables are excluded) and/ or 'normally/typically, the generalisation holds'.

The rationale for this, and other ceteris paribus generalisations, is that there remains an important relationship between the variables in question, in this case moral responsibility and alternative possibilities, despite the existence of exceptions. Leeway and source in/compatibilists present us with a false dichotomy, since we can maintain, with source in/compatibilists, that FSCs do count as genuine counterexamples to PAP, while allowing, with leeway in/compatibilists, that the ability to do otherwise is still integral to an account of moral responsibility.

The primary motivation for $\mathrm{CP}(\mathrm{PAP})$, then, derives from the (assumed) plausibility of both PAP and FSCs. In what follows, §2-4, I shall answer objections to $\mathrm{CP}(\mathrm{PAP})$ and, by so doing, further elaborate the content of the proposal. Finally, in $\S 5$, I shall return to the issue of motivating the view.

\section{Making Room for CP(PAP)}

$\mathrm{CP}(\mathrm{PAP})$ might be considered a naive, short-sighted reaction to FSCs. Against $\mathrm{CP}(\mathrm{PAP})$, the following reasoning may be employed:

a) If PAP is only true ceteris paribus, then we have exceptions to PAP.

b) If we have exceptions to PAP, this shows that we can be morally responsible for our action even though we lack the ability to do otherwise.

c) So whether or not an agent has the ability to do otherwise doesn't matter when making ascriptions of moral responsibility.

Here, the move from b) to c) is highly questionable. Ceteris paribus laws or (less contentiously) generalisations in the special sciences are often employed in explanations of some target phenomenon. These generalisations are not rejected, despite exceptions, nor are they regarded as irrelevant, or uninformative when characterising the phenomenon in question.

Take, for example, Sober's example of 'Darwin's conditional' (Sober 1984, p.28):

If (i) organisms possessing a property $\mathrm{P}$ are better able to survive and reproduce than organisms possessing an alternative property $\mathrm{P}^{\prime}$, and (ii) $\mathrm{P}$ and $\mathrm{P}^{\prime}$ are heritable, then (iii) the proportion of organisms in the population having $\mathrm{P}$ will increase.

Now this, as Sober points out, is only true ceteris paribus. It might just so happen that many more organisms possessing property $\mathrm{P}$ are wiped out in 
freak disasters; or the effects of genetic drift might be particularly significant, etc. But, despite these exceptions, we think that this generalisation is important in explanations of organisms' traits around us. We can appeal to this generalisation to explain why such and such a species has this feature, and make counterfactual assertions regarding how the species might have turned out differently in other environments. The generalisation matters, even though it is not the only thing that matters. In the same way, we might argue, we can often explain why an agent is not morally responsible for an action by appealing to the fact that the agent was unable to perform any alternative action, even though we acknowledge that this is not the only factor relevant to assessing the agent's responsibility for the act.

The same is true of other useful, ceteris paribus, generalisations. For example, take a generalisation from folk psychology, which might be appealed to in a functionalist analysis of pain, such as, 'if $\mathrm{A}$ is in pain then, ceteris paribus, A will seek relief from the pain'. There may be instances where an agent welcomes pain, perhaps they feel that this is what they deserve. But, still, this generalisation may be thought to comprise part of the analysis of pain. Analytic functionalists, for instance, embrace this conclusion:

we are not obliged to define an experience by the causes and effects of exactly all and only its occurrences. We can be content rather merely to identify the experience as that state which is typically caused in thus-and-such ways and typically causes thus-and-such effects, saying nothing about its causes and effects in a (small) residue of exceptional cases. (Lewis 1970, p.104)

Defenders of CP(PAP) might similarly argue that although there are exceptions to PAP, this doesn't mean that the ability to do otherwise isn't essential to an analysis of moral responsibility, that we can understand what it is for an agent to be morally responsible for an action independently of grasping facts about what alternatives are open to them.

Following the Analytic Functionalist's lead, we can formulate a theory of moral responsibility which brings together these different strands by embracing a functionalist analysis of this notion. ${ }^{4}$ The guiding idea is that we should treat 'moral responsibility' as a theoretical concept, which gets its meaning via its role in mature folk theory. ${ }^{5}$ By 'mature' here, I mean

4 A defence of $\mathrm{CP}(\mathrm{PAP})$ does not require a functionalist analysis of moral responsibility, but I do think this way of conceiving matters is helpful. See Jackson (1998, chapter 5) for a functionalist analysis of freedom.

5 Although the view is closely associated with Analytic Functionalism in the philosophy of mind, where mental concepts are defined in terms of their referent's causal inputs, interrelations and outputs, we needn't think of moral responsibility being defined by a series of inputs and outputs. Like Menzies' (1996) theoretical definition of causation in terms of platitudes, the idea is rather that principles that guide our ascriptions of moral responsibility can be utilised to give a theoretical definition of that term. 
that theory we would end up with given maximal critical reflection. It is the theory that makes best sense of puzzling scenarios, intuitions about particular cases, general guiding principles, etc. So what we are after is the theory that most elegantly and informatively codifies our various folk intuitions regarding moral responsibility.

Once we have our folk theory, we can then turn this into an explicit functional definition of moral responsibility by utilising the Ramsey-CarnapLewis technique. ${ }^{6}$ For instance, just to offer a simplistic example to illustrate the idea, we might say something such as:

Moral responsibility is the relation that holds between agent(s) $S$ and act/ omission A when $S$ is rational; typically, $S$ performs A on the basis of reasons with which she identifies; ceteris paribus, $S$ is able to refrain from Aing, etc.

As well as being an approach open to compatibilists and incompatibilists alike, a functionalist theory of moral responsibility has the advantage of not requiring a simple formula which is both necessary and sufficient for moral responsibility. If, as seems likely, a multiplicity of factors is relevant to moral responsibility, these could all be incorporated into the postulate of the folk theory of moral responsibility.

This point is worth stressing, as it allows us to maintain that although alternative courses of action being open to the agent is morally significant, and can take precedence in determining an agent's moral responsibility for a certain action, it is not the only morally significant factor. These different factors will usually co-exist peacefully together, but there will be special occasions when they come into conflict. To take an analogy, normally, Darwin's conditional and genetic drift do not lead to different outcomes. But there are occasions when the consequences of genetic drift outweigh those of natural selection. ${ }^{7}$ On such occasions, Darwin's conditional is outweighed by further, mitigating factors; but it remains an important explanatory principle that can be used to account for various phenomena. Similarly, we might suggest that although, at times, a

6 For a clear statement of the Ramsey-Lewis-Carnap approach to theoretical terms, see, for instance, Lewis 1970. The basic idea is that we turn our folk theory into an explicit definition of our theoretical term (T-term) 'moral responsibility', by rewriting the discourse in property name form and replacing our theoretical term with an existentially bound variable. If any other terms in our folk theory are defined in relation to 'moral responsibility', we need to eliminate reference to them by treating them as theoretical terms too, and so replacing them with distinct variables. In this way, by utilising only logical vocabulary and already understood terminology (O-terms), we can derive individual definitions for our theoretical terms from the folk theory.

7 This is particularly so in small populations, where it is more likely that frequencies of outcome will diverge from probabilities (see Sober $1984 \S 4.2$ for more details). 
combination of further considerations, such as the motive from which the agent acts, can trump PAP, nevertheless, since PAP is embedded in the analysis of moral responsibility, it remains a forceful component of our ascriptions of moral responsibility.

\section{Saving CP(PAP) from Vacuity}

Like all ceteris paribus laws (or generics), CP(PAP) faces the problem of vacuity. If PAP has exceptions, when is it legitimate to appeal to it? Can we say what these exceptions are without circularity? Without saying, in other words, that moral responsibility requires alternative possibilities, except in those cases when an agent is morally responsible but cannot do otherwise?

A defender of $\mathrm{CP}(\mathrm{PAP})$ can begin by noting that some exceptions are legitimate, in part, because the action satisfies most of the other requirements of moral responsibility. Just as we might argue that an agent is in pain because, even though they are not displaying obvious signs of pain, such as wincing and groaning, one of their mental states satisfies most of the other conditions definitive of pain, so too we can suggest that a particular action might count as a legitimate exception because it satisfies most of the platitudes definitive of moral responsibility.

In times of conflict, however, it would be good to have some guidelines concerning which principles trump which. On what Strevens calls the "narrowing approach' (2012, p.660) to CP-laws, the ceteris paribus clause restricts the range of situations in which the generalisation/law/principle is claimed to hold. Popular amongst these restrictions are appeals to 'normal' or 'ideal' conditions. So we say something of the form:

$\mathrm{CP}($ As are $\mathrm{F})$ iff in normal or ideal or $\mathrm{c}_{1}-\mathrm{c}_{\mathrm{n}}$ conditions, all As are $\mathrm{F}$.

Consider, for instance, the generic or $\mathrm{CP}$-generalisation, ' $\mathrm{CP}$, cats have four legs'. Tibbles is a counter-instance to this claim. Unfortunately, she had to have a leg amputated after an accident. But we regard Tibbles as a permissible counter-instance to the claim, because we recognise that she is not normal. Borrowing from Asher and Morreau (1995), we might say something of the form, if things had gone normally for Tibbles, then she would have had four legs. Contrast the case of Tibbles, with one where we discover a breed of cats (genetically similar to all other breeds of cats), which are all born with three legs. If the same 'normal' biological processes resulted in these cats, then our CP-law would be undermined. So it is not vacuous, since it can be falsified.

This highlights a recent trend, in relation to the special sciences, to understand ceteris paribus laws in terms of causal mechanisms. Central to 
this approach is the idea that whether or not the conditions are 'normal' or 'ideal' depends upon whether or not the target causal mechanism is being frustrated. ${ }^{8}$ The ceteris paribus clause is restricted to those occasions were the target causal mechanism is exemplified. Cases where cats have had legs amputated after accidents are not counter-instances to the claim that ' $\mathrm{CP}$, cats have four legs', as they are the result of a different kind of causal mechanism, which interferes with the results of the natural, biological causal mechanism which the CP generalisation is about. So the 'normal' or 'ideal' conditions for the $\mathrm{CP}$ generalisations exclude the working of this interfering causal mechanism.

This might give rise to worries regarding the intelligibility of such claims outside the special sciences, where it may be untenable to specify what conditions count as 'normal' by reference to some target causal mechanism. But such a rationale for $\mathrm{CP}(\mathrm{PAP})$, at least if interpreted loosely, does not seem out of the question. Like ceteris paribus claims in the special sciences, what's 'normal' needs to be understood in light of the practice within which the CP-claim is proposed. ${ }^{9}$ The target phenomenon, and significant causal mechanisms, are set by the enquiry in question. Proponents of $\mathrm{CP}(\mathrm{PAP})$ can suggest that, standardly, when we talk of agents being unable to do otherwise, we are attempting to latch onto a kind of deliberative process that compels or necessitates an agent's making a particular decision or, more generally, a process which compels or necessitates an agent's acting in a certain way. (In support, we might point to the existence of brain manipulation, phobias, indoctrination etc., suggesting that this process of, what Fischer refers to as 'actual-sequence compulsion' 1982 , p.84, is a feature which is potentially common to the different cases, and explains why we find them troubling.) When we say that an agent could not have done otherwise, we suppose that this is because the agent's actions (mental and otherwise) are the result of such a necessitating process.

FSC cases, however, are significant since they show that this is not always the case. It may be that the right kind of necessitating process is not in place, but it nevertheless appears to be because of an inactive backup mechanism that mimics its presence. By 'inactive backup' here, I mean, roughly, an entity (be that a device, possible threat, lesion etc.) which could be causally efficacious with respect to a certain effect (e.g. the death of the

8 See, for example, Nickel, 'what makes an A relevantly normal is that it goes through a theoretically important mechanism for the purposes of a particular target of inquiry' (2010, p.19), and Strevens, 'Ceteris paribus, in conditions Z, Fs are G' is true iff 'When conditions $O$ hold, then by way of target mechanism $M$, conditions $Z$ and the property $F$ bring about $G^{\prime}$ (2012, p.660).

9 For defences of this claim, see for instance, Pietroski and Rey (1995), Lange (2002) and Nickel (2010). 
dictator, the taking of the drug, etc.), but which was not in the actual circumstances. ${ }^{10}$ Such backups ensure, of the situation taken as a whole, that the agent could not have done otherwise. But since the backup guarantees this result, regardless of the processes' features active in the agent, assessments of whether or not the agent could have done otherwise in that situation fail to track the existence of the necessitating processes we are interested in.

The rationale for $\mathrm{CP}(\mathrm{PAP})$, then, can be seen as similar to that in the special sciences. The suggestion is that $\mathrm{CP}(\mathrm{PAP})$ states a generalisation about the relationship between moral responsibility and active processes within the agent that necessitate outcomes. ${ }^{11}$ As such, the CP clause is meant to exclude any interfering, alternative causal factors. In the case of Jones, the interfering presence of Black and his device means that, in that situation, no alternative is open to Jones. But this is an alternative mechanism from the one $\mathrm{CP}(\mathrm{PAP})$ is attempting to latch onto, namely one where

In 'blockage' FSCs (e.g. see Mele and Robb 1998), the backup is not intuitively inactive since, here, Black sets off a process which blocks certain alternatives. However, it is nevertheless intuitive to say that the backup is inactive with respect to bringing about the action, since the alternative process is not supposed to interfere or affect the causal process in any way. So the processes which are 'active' in the agent should be understood as those which are actually causally efficacious with respect to the specified outcome. Admittedly, more needs to be said here in order to clarify the proposal. But I hope that the rough outlines given will suffice for the purposes of this section, which is merely to say why the vacuity objection is not decisive.

Paraphrasing Strevens, we might go as far as suggesting that the truth conditions of CP (PAP) can be spelt out as follows: When conditions $O$ hold (i.e. there are no inactive backups about), then by way of a necessitating process $P$, the lack of ability to do otherwise removes (or at least mitigates) the agent's moral responsibility for the act. There is good reason, however, to maintain the $\mathrm{CP}$ clause. First, although the CP clause is, in principle, dispensable on Streven's account once we have a complete understanding of the mechanisms involved, such understanding is rare. He writes, 'Typically scientists will have only very partial knowledge of the target mechanism's operation conditions. . scientists literally do not comprehend much of the content of their own hypothesis' (2012, p.661). I take our position to be similar in the case at hand, thus warranting continued use of the CP clause. We are not in a position to exclude the possibility that there might be further legitimate exceptions to PAP because, as I shall stress presently, we have no account of what the necessitating processes are. The proposal here is thus not a replacement for the $\mathrm{CP}$ clause, but rather a suggestion of how we could construe $\mathrm{CP}(\mathrm{PAP})$ so as to answer the charge of vacuity. Second, one may agree with the general strategy being proposed here, whilst offering some other construal of the CP clause. It may be useful to liken the $\mathrm{CP}$ clause to a term such as supervenience. This designates a relation with clearly identifiable features which can be appealed to in a wide array of areas. But different accounts of why the supervenience relation holds can be offered. Similarly, here, CP generalisations are a feature of numerous fields of enquiry, and the $\mathrm{CP}$ clause flags up the fact that such generalisations have certain common features. But differing accounts of the $\mathrm{CP}$ clause may be given in different areas. So one might agree with $\mathrm{CP}(\mathrm{PAP})$, but offer some other reading of the $\mathrm{CP}$ clause. (For alternative approaches, one could look at work in ethics, for instance, see Lance and Little 2004.) 
the agent's deliberative, or other active processes necessitate a certain outcome. Since the CP generalisation does not concern this kind of backup causal mechanism, its presence renders the circumstances 'abnormal' or 'not ideal' in this context of enquiry. As in the case of Tibbles, we can say that had things gone normally for Jones (i.e. had there been no funny business going on with backups), then he would have been able to do otherwise. Once we have screened off the abnormal or disturbing factor, PAP is true. So this counts as a permissible exception to PAP, as the underlying rationale for PAP still holds.

As it stands, the proposed elaboration of CP(PAP) is clearly incomplete. It requires supplementing with an analysis of what kind of active processes count as 'necessitating,' or with, what I think amounts to the same thing, an analysis of what it means to say that the agent could not have done otherwise, once we have screened off the inactive backups. At this point, CP (PAP) could be developed in a number of different ways, in accordance with both incompatibilism and compatibilism. The simplest account is an incompatibilist one: if there are nomologically possible worlds where all the facts about the agent's environment, plus facts about the agent's active processes (so minus any inactive backups), are held fixed, and she does do otherwise, then she is able to do otherwise. But a compatibilist might instead turn to Fischer and Ravizza's influential account (1998), arguing that the duplicated active processes could have resulted in a different outcome if they would have, given sufficient reason to do otherwise. ${ }^{12}$ Alternatively, one might offer a contextual construal of ' $\mathrm{S}$ has the ability to do otherwise'. Independent of a context, the claim that ' $S$ has the ability to do otherwise' does not express a complete proposition. When assessing whether an agent has the ability to do otherwise, it is the context that determines which features of the agent's active processes and environment should be held fixed. ${ }^{13}$

Due to the enormity of the topic, and the fact that a number of analyses could be plugged into this elaboration of $\mathrm{CP}(\mathrm{PAP})$, this issue will be set aside here. But it is significant when we consider the question of what counts as an illegitimate counter-instance to $\mathrm{CP}(\mathrm{PAP})$. If $\mathrm{CP}(\mathrm{PAP})$ isn't vacuous then, as in the case of Tibbles, it seems that there should be cases which falsify it. Consider, for instance, Mele's controversial zygote case (2006, p.188):

\footnotetext{
12 Being source compatibilists, Fischer and Ravizza wouldn't phrase it this way but it is close to the spirit of their suggestion. For a similar view from a leeway compatibilist, see Smith 2003. I am sceptical of this kind of approach for familiar reasons (see, for instance, the cases by Mele 2006), preferring the contextualist analysis suggested above. related defence of a context relative view of 'cans'.
} 
Designed Ernie: Minor Goddess, Diana, creates zygote Ernie. A master at biological engineering with a full grasp of all the deterministic laws, she fashions zygote Ernie so that, at time t, Ernie can do no other than murder Eric.

One might plausibly argue that this is an illegitimate counterexample to $\mathrm{CP}(\mathrm{PAP})$. There is no nearby possible world where, absent an inactive backup, Ernie could have done otherwise. The actual mechanism in play is one which was biologically engineered to ensure that Ernie had no choice other than to murder Eric at time t. So if Ernie is morally responsible for the outcome, $\mathrm{CP}(\mathrm{PAP})$ is false. This assessment, however, crucially depends upon the analysis of 'could have done otherwise.' I think the context arguably demands an incompatibilist reading of 'could have done otherwise,' since the example draws our attention to the fact that Ernie couldn't have done otherwise given the past and the laws of nature. Given this assessment, Designed Ernie would count as a successful counterexample to $\mathrm{CP}(\mathrm{PAP})$. But we might argue, alternatively, that (depending on the details of the case) Ernie was able to do otherwise in the absence of backups, since if he had sufficient reason to do otherwise, he would have succeeded, so this doesn't count as a genuine counterexample to $\mathrm{CP}(\mathrm{PAP})$. We cannot say, then, what counts as a genuine counterexample to $\mathrm{CP}$ (PAP) until the present proposal has been supplemented with an analysis of 'could have done otherwise'. But, nevertheless, enough has been done to show that the analysis is not vacuous. If you disagree with my assessment of Designed Ernie, then you can simply switch this example for one where, given the actual processes occurring in the agent and in the absence of any backups, the agent (according to your preferred construal of 'could have done otherwise') couldn't have done otherwise. If, nevertheless, it is true that the agent is morally responsible for their action, then this is an impermissible counter-instance to $\mathrm{CP}(\mathrm{PAP})$. So $\mathrm{CP}(\mathrm{PAP})$ is not vacuous.

One final note of clarification: this approach is not a version of the 'flicker of freedom' strategy. ${ }^{14}$ It does not attempt to find some alternative, no matter how slight or coerced, to make PAP true in FSCs. That Jones would have had an alternative open to him, in the absence of the backup, does not provide Jones with an alternative. But this is okay, since the aim is only to justify the claim that this is a legitimate counter-instance to PAP,

\footnotetext{
14 This kind of objection was famously introduced into the literature by Fischer, see for instance 1994, p.180. He argues that the alternative possibilities that arguably remain in FSCs are not sufficiently robust enough to ground ascriptions of moral responsibility because they are coerced.
} 
not to try to find an alternative possibility. Once we have rejected the assumption that for PAP to be significant to attributions of moral responsibility, it must be a feature of every morally responsible act, we can simply embrace the existence of exceptions.

\section{Globalising FSCs}

An objection: doesn't the globalisation of FSCs scupper the attempted reconciliation between FSCs and the intuitions driving PAP?

Globalised Frank: Black decides he enjoys being in control of every aspect of Frank's life. So Black leaves the device in, and programmes his desired outcome for every decision that Frank will ever make. However, by an amazing series of coincidences, the device proves redundant on every occasion (based on Mele and Robb 1998, p.110).

As, arguably, Frank is morally responsible for all of his decisions, despite it not being true of him that he can normally do otherwise, we seem to have a counterexample to $\mathrm{CP}(\mathrm{PAP})$.

Let's grant, at least for the sake of argument, that Globalised Frank is genuinely morally responsible for his decisions, and so, statistically speaking, Frank is not normally able to do otherwise. Even so, one man's paralysis doesn't make it false that, 'ceteris paribus, human beings can walk'. Likewise, it can still be true that, 'ceteris paribus, PAP,' so long as every exception can be accounted for. In Globalised Frank, given that the backup device always remains inactive, we can argue that every set of circumstances in which Frank forms a decision is special or abnormal. Frank, on each occasion, has an ability to do otherwise once we have screened off the disturbing factor of the inactive backup device. So $\mathrm{CP}(\mathrm{PAP})$ is still true, as Frank is always in highly unusual circumstances, where there are countervailing factors rendering each of his decisions a legitimate exception to $\mathrm{CP}$ (PAP).

Could we globalise the globalising cases, so that everyone was like Frank? We could have some evil demon that implants a device, like that described in Globalised Frank, in all human beings so that, like Frank, we only have one outcome available to us on every occasion. But, of course, by a series of remarkable coincidences, this one outcome is always chosen by everyone anyway, so the device never blocks anyone's actual decisions. Call this case Global Devil.

Global Devil seems to pose a problem for CP(PAP). The device counts as an inactive backup, since it never actually blocks the outcome of anyone's decision process. But if everyone was fitted with such a device, then the claim that, normally, morally responsible agents can do otherwise would 
be false. ${ }^{15}$ So the very circumstances which are taken to be mitigating can lead to the thesis being false.

The solution to this problem comes from a more nuanced reading of 'normally, morally responsible agents can do otherwise,' which aligns it closer to the proposed interpretation of 'ceteris paribus, morally responsible agents can do otherwise'. One perfectly acceptable way of reading 'normally' here is to say that, statistically speaking, the number of agents who are morally responsible for their actions, and can do otherwise, are in the significant majority (call this majority-normal). It is concerned with the frequency of which an agent is both morally responsible and able to do otherwise. In Global Devil, agents cannot majority-normally do otherwise when they are morally responsible for their acts, since they never actually can do otherwise.

This sense of 'normal', however, is not the one of concern here. In $\S 3$, 'normal' was defined in relation to our practice of holding people accountable. We privilege a certain set of actual conditions, where the deliberative process is not necessitated by what precedes it, and take this to define the 'normal situation' across possible worlds (call this privileged-normal). Often, in the actual world, this set of privileged actual conditions will be statistically prevalent, so the generalisation will be true of the majority of cases. ${ }^{16}$ But when we are dealing with hypothetical situations, when conditions are assumed to be markedly different from the actual world, this certainly won't be the case. So the different senses of normality will come apart.

Terrence Horgan has raised with me the question of what 'can do otherwise' means in the mouths of inhabitants of the Global Devil environment. As the thought experiment is set up, I am supposing that we might be the inhabitants of Global Devil, and so we would mean just what we take ourselves to mean by attributions of 'could have done otherwise' (we would just be mistaken in thinking it ever applied to ourselves). Here, following standard practice in Frankfurt-style cases, I am relying on an intuitive understanding of 'could have done otherwise'. If, for instance, the demon's device would have killed us if we had deviated from the programmed outcomes, there is an intuitive sense in which we couldn't have done otherwise, no matter what analysis of this phrase we adopt. Even if the inhabitants of the Global Devil world did mean something else by their attributions of 'could have done otherwise', however, this wouldn't matter for the purposes of forming a counterexample to $\mathrm{CP}(\mathrm{PAP})$. The case still poses a threat so long as there are instances in which we would judge the inhabitants of this world to be morally responsible for their actions, despite the fact that these inhabitants are never able to do otherwise by our standards.

Although the privileged actual conditions might not be statistically prevalent, rendering the generalisation untrue in the majority-normal sense. Take, for instance, 'Turtles are long-lived'. This is true even though most turtles are not long-lived because most newborn turtles are eaten in their race to the sea. But nevertheless we count the generic claim as true, since we are privileging a set of conditions which holds fixed a turtle's slow metabolism, and takes the presence of predation to be a disturbing, abnormal factor (see Nickel 2010, in particular p.22, for more discussion of this example). 
To illustrate, consider the claim that 'ceteris paribus, penicillin cures syphilis' and 'normally, penicillin cures syphilis'. It might be the case that, due to the severity of a patient's allergic reaction to penicillin, their syphilis cannot be effectively treated with penicillin. But given the empirical fact that such allergic reactions are uncommon, we can move from the ceteris paribus clause which states, 'in the absence of severe allergies...' to the claim that, 'majority-normally, penicillin cures syphilis.' But now suppose that the population changed radically, so that the majority were now allergic to penicillin. In such a case, it would no longer be true to say, 'majoritynormally, penicillin cures syphilis', but it would still be true to say that 'ceteris paribus (in the absence of allergies and other disturbing factors or privileged-normally), penicillin cures syphilis.'

Similarly, in the case of Global Devil, we are asked to consider an (arguably) conceptually possible scenario were the population differs, we assume, substantially from our own. In such a far away possible world, the background empirical assumption that the population are, majority-normally, able to do otherwise is false. If an agent is ever morally responsible for an act in such a world, it cannot be because she can majority-normally do otherwise, but rather because, in the absence of disturbing factors (or privileged-normally), she could have done otherwise. So the Globalising cases do not undermine $\mathrm{CP}(\mathrm{PAP})$.

\section{An Application: Moral Responsibility for Omissions}

In section one, I suggested that $\mathrm{CP}(\mathrm{PAP})$ was motivated by its ability to combine two compelling considerations: PAP and FSCs. This is my primary reason for accepting $\mathrm{CP}(\mathrm{PAP})$. I want to end, however, by briefly suggesting one further benefit. I shall argue that $\mathrm{CP}(\mathrm{PAP})$ can accurately track our intuitive responses to two different kinds of cases involving moral responsibility for omissions - cases which other existent accounts cannot together accommodate.

Here are a couple of tricky cases involving moral responsibility for omissions:

Finked Frank: Frank is walking along a beach and sees a child drowning. A Frankfurt device has been implanted in him such that, if he tries to decide to save the child, the device will take over, rendering Frank incapable of so deciding. But, as it happens, Frank decides to ignore the child's plight and the device is never triggered. (Based on Frankfurt 1994, p.622)

Enabled Frank: Frank decides not to save a drowning child. If Frank had attempted to decide to save the child then, unbeknownst to him, he would have been overwhelmed by a debilitating phobia, rendering him unable to make that decision. However, a kindly fairy godmother has fitted Frank 
with an enabling device. This would have disabled his phobia immediately on triggering, leaving Frank able to decide to save the child.

(Based on Levy 2008, p.234)

These cases pull us in different directions. Enabled Frank indicates that the ability to do otherwise does matter in ascriptions of moral responsibility. One reason why Frank is still morally responsible for failing to decide to save the child is that he could have made that decision. ${ }^{17}$ FSCs involving omissions, such as Finked Frank, however, indicate that an agent can be morally responsible for their omission despite not being able to do otherwise.

Fortunately, CP(PAP) can accommodate both types of cases. Take, first, the case of Finked Frank. Here, we can assess the manner and motive of the agent's decision process and this, combined with the inactivity of the backup, can trump PAP. Frank makes a decision not to save the child, and given the proposed interpretation of $\mathrm{CP}(\mathrm{PAP})$, he is responsible for that decision. ${ }^{18}$ Although he couldn't have decided otherwise in the circumstances, since he satisfies the other conditions on moral responsibility, and the backup does not impact in any way upon the deliberations leading up to his decision, we are entitled to screen off the presence of the inactive backup to see what would have happened in near duplicate situations. As we can assume that, in these worlds, Frank is able to decide to save the child, Frank is responsible for his decision. ${ }^{19}$

What of Enabled Frank? In the very circumstances in which Frank finds himself, he is able to decide otherwise. It doesn't matter that Frank can only decide otherwise because of a special enabling device that has been put in place for him in those particular circumstances. To be morally responsible for an action, it is not the case that the agent must have been able to refrain from that action in a good proportion of nearby counterfactual situations. An agent's action satisfies CP(PAP) even if he is only able to do otherwise given his actual, highly unusual, circumstances. Since Frank can do otherwise given the circumstances, we have no counter-instance to PAP and so no more needs to be said.

$\mathrm{CP}(\mathrm{PAP})$, then, seems uniquely well-placed to capture our intuitions here. Leeway in/compatibilists cannot accommodate FSCs, including those

17 Levy's (2008) enabling cases can be employed against Fischer and Ravizza's account (see 1998 p.130-1, their condition 2 is not met in this case). Similarly, the variation on Levy's case outlined above causes problems for McIntyre's analysis (1994, p.466-7, her condition b is not met in this case) and Clarke's account (1994).

In cases of unintentional omissions, such as forgetting to babysit (see Clarke 1994, p.203), we can similarly consider whether any Frankfurt-type device or busy-body (which/whom would have intervened in the process if it looked as if the agent was going to remember...) remained inactive. 
involving omissions. Source in/compatibilists stumble on Levy's enabling cases, since they show that being able to act/decide differently, even if this is due to an extrinsic enabling device, can place the agent in the hot seat. But as $\mathrm{CP}$ (PAP) states that, normally, the ability to do otherwise matters, but there are certain principled counter-instances, it can account for the complexity of our responses in such cases. Insofar as we find both enabling cases and FSCs convincing, then, these cases support CP(PAP).

\section{Conclusion}

The negative claim that alternative possibilities are not strictly necessary for moral responsibility doesn't provide us with a positive account of the relationship between moral responsibility and the ability to do otherwise. There is middle ground between source and leeway in/compatibilism, and it is worth exploring due to the intuitive plausibility of both FSCs and PAP. CP (PAP), and its proposed elaboration here, offers us a promising way of combining the intuitions on both sides. ${ }^{20}$

\section{References}

Asher, Nicholas and Morreau, Michael (1995). 'What Some Generics Mean,' in Carlson C. and Pelletier J. (eds.) The Generic Book, Chicago: The University of Chicago Press, pp.300-338.

Carlson, Gregory and Pelletier, Jeffery eds. (1995). The Generic Book, Chicago: The University of Chicago Press.

Clarke, Randolph (1994). 'Ability and Responsibility for Omissions,' Philosophical Studies, vol. 73, pp.195-208.

Fischer, John Martin (1982). 'Responsibility and Control,' The Journal of Philosophy, vol. 79, pp.24-40.

— (1994). The Metaphysics of Free Will, Oxford: Blackwell. and Ravizza, Mark (1998). Responsibility and Control: A Theory of Moral Responsibility, Cambridge: Cambridge University Press.

Frankfurt, Harry (1969). 'Alternate Possibilities and Moral Responsibility,' Journal of Philosophy, vol. 66, pp.829-39.

(1994). 'An Alleged Asymmetry Between Actions and Omissions,' Ethics, vol. 104, pp.620-623.

Horgan, Terrence (1979). 'CCould', Possible Worlds, and Moral Responsibility,' Southern Journal of Philosophy, vol. 17, pp.345-58.

20 Many thanks to Joel Smith and Terrence Horgan for their helpful comments. Thanks also to participants at the Free Will and Moral Responsibility Workshop, University of Manchester and the University of Leeds Departmental Philosophy Seminar. Work on this paper was generously funded by a grant from the Arts and Humanities Research Council. 
Jackson, Frank (1998). From Metaphysics to Ethics, Oxford: Oxford University Press.

Kratzer, Angelika (1981). 'The Notional Category of Modality,' in H. J.

Eikmeyer and H. Rieser (eds.), Words, Worlds, and Contexts. New Approaches in Word Semantics, Berlin: de Gruyter, pp.38-74.

Lance, Mark and Little, Margaret (2004). 'Defeasibility and the Normative

Grasp of Context,' Erkenntnis, vol. 61, pp.435-455.

Lange, Marc (2002). 'Who's Afraid of Ceteris-Paribus Laws? Or: How I Learned to Stop Worrying and Love Them,' Erkenntnis, vol. 57, pp.281-301.

Levy, Neil (2008). 'Counterfactual Intervention and Agents' Capacities,' Journal of Philosophy, vol. 105, pp.223-239.

Lewis, David (1970). 'How to Define Theoretical Terms,' The Journal of Philosophy, vol. 67, pp.427-46.

McIntyre, Alison (1994). 'Compatibilists Could Have Done Otherwise: Responsibility and Negative Agency,' Philosophical Review, vol. 103, pp.453-488.

Mele, Alfred (2006). Free Will and Luck, Oxford: Oxford University Press.

Mele, Alfred and Robb, David (1998). 'Rescuing Frankfurt-Style Cases,' Philosophical Review, vol. 107, pp.97-112.

Menzies, Peter (1996). 'Probabilistic Causation and the Pre-Emption Problem,' Mind, vol. 105, pp.85-117.

Nickel, Bernhard (2010). 'Ceteris Paribus Laws: Generics and Natural Kinds,' Philosophers' Imprint, vol. 10, no. 6.

Pietroski, Paul and Rey, Georges (1995). 'When Other Things Aren't Equal: Saving Ceteris Paribus Laws From Vacuity,' British Journal for the Philosophy of Science, vol. 46, pp.81-110.

Smith, Michael (2003). 'Rational Capacities, or: How to Distinguish Recklessness, Weakness, and Compulsion,' reprinted in his Ethics and the A Priori (2004), Cambridge: Cambridge University Press, pp. 114135.

Sober, Elliott (1984). The Nature of Natural Selection, Chicago: The University of Chicago Press.

Strevens, Michael (2012). 'Ceteris Paribus Hedges: Causal Voodoo That Works,' The Journal of Philosophy, vol. 109, pp.652-675.

Whittle, Ann (manuscript). 'On An Alleged Asymmetry Between Acts and Omissions.' 